\title{
IMPRESSORA CONSTRUÍDA DE LEGO : UM OBJETO DE APRENDIZAGEM PARA APLICAÇÃO DE GEOMETRIA PLANA
}

\author{
ANDRÉA CANTARELLI MORALES \\ PATRÍCIA GIACOMELLI \\ TAtiele Bolson MORO \\ Francisco CATELLI \\ Universidade de Caxias do Sul (UCS), Caxias do Sul, Rio Grande do Sul, Brasil
}

\begin{abstract}
Resumo: O presente artigo trata da utilização de uma impressora, construída com LEGO;, por bolsistas de iniciação científica do curso de Engenharia de Controle e Automação, como objeto de aprendizagem para uma aplicação do conteúdo de Geometria Plana. O referencial teórico, subsidiado por objetos de aprendizagem e metodologias de aprendizagem ativa, deram suporte para o desenvolvimento da atividade que consistia em, dada uma figura geométrica, calcular os ângulos em sequência para formar a figura depois; o comprimento de reta e o ângulo eram digitados em sequência no aplicativo que faz comunicação com a impressora e imprime a imagem. Através do resultado era possível identificar eventuais erros nos cálculos, com a interferência do professor para a compreensão e posterior correção por parte dos estudantes. A atividade proporcionou motivação e interesse, mediada pelo trabalho em equipe, e uma análise reflexiva sobre o aprendizado do conteúdo.
\end{abstract}

Palavras-chave: Aprendizagem Ativa. Objeto de Aprendizagem. Metodologias de Aprendizagem. Geometria Plana.

\section{INTRODUÇÃO}

O presente artigo trata da aplicação de um Objeto de Aprendizagem (OA) utilizado em uma turma de $2^{\circ}$ ano do Ensino Médio de uma escola particular do município de Caxias do Sul/RS. O referencial teórico adotado abarca a literatura sobre Objetos de Aprendizagem (WILEY, 2000; TAROUCO, 2014; ZARPELON et al., 2018; NESI et al., 2019) e Aprendizagem Ativa (AA) (DEWEY, 1976; ALMEIDA, 2018; BES et al., 2019; PUHL et al., 2017; SANTOS; LEITE, 2019) para conceituar a temática proposta. Em relação aos OAs, pode-se dizer que estes têm por objetivo dar suporte ao processo de aprendizagem, sendo recursos que auxiliam a construção do conhecimento. Já a AA tem por finalidade estimular a curiosidade e facilitar a aprendizagem. Assim, discorre-se sobre a abordagem do ensino de geometria plana, valendo-se de um OA.

A construção de um OA que constitui uma impressora foi desenvolvida com peças de conjuntos para robótica, do tipo LEGO $^{\circ}$ Mindstorms, integrada a um aplicativo de celular. Através do aplicativo o aluno pode informar os dados (comprimento dos 
segmentos de reta e ângulos) para que a impressora realize o traçado das figuras geométricas desejadas.

O objetivo desta investigação é observar a aplicação de um objeto de aprendizagem no desenvolvimento de uma atividade de cálculos sobre geometria plana e, para tanto, utilizou-se a impressora construída de $\mathrm{LEGO}^{\circ}$ por bolsista de Iniciação Científica do curso de Engenharia de Controle e Automação através de Projeto de Pesquisa que visa à construção de objetos de aprendizagem para o ensino de Física e Matemática. Para isso, os alunos da turma foram divididos em grupos para realizar os cálculos solicitados pela professora. Após os cálculos prontos, os alunos, valendo-se do aplicativo, encaminhavam os resultados à impressora e esta realizava a impressão dos traços das retas e ângulos informados por eles. Ao longo do processo, percebeu-se que - OA permitiu aos alunos visualizar a aplicação dos cálculos, observando o resultado destes na figura impressa e, por consequência, as reformulações que seriam necessárias ou não. Por fim, apesar de não estarmos analisando nesse processo a questão da aprendizagem, foi possível observar o empenho e o engajamento dos alunos, bem como a curiosidade e motivação pela utilização de um objeto de aprendizagem durante a aula, que permitiu aos alunos a visualização da aplicação dos cálculos, bem como dos erros.

REFERENCIAL TEÓRICO

\section{OBJETOS DE APRENDIZAGEM}

O objeto de Aprendizagem (OA) pode ser conceituado como uma ferramenta de aprendizagem e instrução, sendo utilizada de diversas formas para o ensino de conteúdo, levando o aluno ao pensamento crítico e facilitando a disseminação de conhecimento. Segundo Tarouco et al. (2014), os OAs podem ser criados em qualquer mídia ou formato, podendo variar de acordo com a concepção da utilidade e importância do objeto para o ensino e aprendizagem, variando de acordo com a abordagem proposta e os aspectos aos quais são associados o uso educacional.

Para Wiley $(2000$, p. 7), um OA é "qualquer recurso digital que pode ser reutilizável para dar suporte à aprendizagem", ou seja, é um elemento que pode se constituir em um módulo provido de conteúdo autoexplicativo, que faz sentido sem ter a necessidade de ser complementado, mas pode abranger conteúdos que se relacionem entre si. Corroborando essa contextualização, Zarpelon et al. (2018) citam que um OA tem o objetivo de funcionar como facilitador no processo de ensino e aprendizagem, devendo determinar os objetivos pedagógicos e ser organizado de forma a ser autocontido, permitindo ser reutilizável em outras atividades. Ainda conforme o autor, os OA possuem diversos formatos e propostas de uso, podendo ser quaisquer materiais eletrônicos que englobam informações destinadas à construção do conhecimento, explicando os objetivos pedagógicos e que estejam organizados de tal forma que possam ser reutilizáveis para outras atividades ou recombinados com outros objetos de aprendizagem. Sendo exemplos de OA: imagens, vídeos, páginas web, animações ou simulações. São características que visam a demanda por interfaces e recursos que 
MORALES, A. C.; GIACOMELLI, P.; MORO, T. B.; CATELLI, F.

estimulem os alunos na busca por novos conhecimentos e propiciem a aprendizagem de um determinado conteúdo (ZARPELON et al., 2018; NESI et al., 2019).

Os objetos de aprendizagem possuem grande significância educacional, possibilitando novas formas de construção do conhecimento. Esses objetos aproximam os alunos dos conceitos, auxiliando a assimilação dos conteúdos em várias áreas do conhecimento, e podem ser reutilizados e combinados com outros objetos, proporcionando um ambiente rico em aprendizagem, além de flexível. Os OA podem promover a aprendizagem desde que exista um planejamento onde sejam enquadrados os propósitos pedagógicos e seus objetivos, tendo critérios para avaliar a qualidade dos objetos de aprendizagem (ZARPELON et al., 2018; NESI et al., 2019).

Pode-se dizer que a vantagem do uso dos OAs é a de propiciar ao aluno variadas oportunidades para que ele realize tantas tentativas quanto desejar para construir hipóteses sobre um determinado conteúdo ou tema. $\mathrm{O}$ aluno ainda pode ter um retorno, oriundo de sua interação com o $\mathrm{OA}$, que irá auxiliá-lo no eventual ajuste de planos e (ou) procedimentos, e ajudá-lo a criar estratégias; porém o professor mantém seu papel de mediador dos conhecimentos trabalhados através do objeto de aprendizagem (TAROUCO et al., 2014).

\section{AprendizAgem ATIVA}

Trata-se de atividades que são desenvolvidas de modo a fazer com que o estudante seja o autor do seu próprio conhecimento, e são denominadas metodologias de aprendizagens ativas. Almeida $(2018$, p. 12) caracteriza metodologias ativas como a "[...] inter-relação entre educação, cultura, sociedade, política e escola, sendo desenvolvida por meio de métodos ativos e criativos, centrados na atividade do aluno com a intenção de propiciar a aprendizagem [...]". Desse modo, não necessitamos ter processos tecnológicos para o desenvolvimento de uma atividade voltada às metodologias ativas, mas sim algo que estimule a curiosidade e que seja articulado pelo estudante, incentivando a autonomia. Esses processos iniciaram com mais intensidade no final do século XIX, quando se começou a questionar a metodologia pedagógica utilizada, denominada hoje como tradicional. Essa metodologia é conhecida por uma postura de passividade por parte do estudante, provocada predominantemente pelo professor que, assumindo-se detentor do conhecimento, repassa o conteúdo para os estudantes, não ocorrendo uma interação neste processo (BES et al., 2019).

Dewey (1976) já afirma que, para aprender, é preciso ter experiência. Porém, é preciso observar as experiências: experimentar somente para comprovar, sem o envolvimento intelectual do estudante, não é producente no processo de aprendizagem. As experiências que envolvem o estudante neste seu processo, além de se constituírem como um facilitador no desenvolvimento de sua aprendizagem, também facultam outras habilidades, como trabalho em equipe, raciocínio crítico e até a criatividade, habilidades estas que serão úteis em seu futuro profissional.

Pesquisas vêm sendo realizadas (PUHL et al., 2017; SANTOS; LEITE, 2019) e constata-se que a utilização de metodologias ativas tem sido um excelente aliado para um maior engajamento dos estudantes nas atividades, além de favorecer a formação de estudantes mais criativos. Os procedimentos utilizados nas metodologias de aprendizagem ativa são condizentes com os estudos de Santos (2008), nos quais fica 
estabelecido que, para ocorrer a aprendizagem, há a necessidade de quatro condições básicas: a) motivação, que pode ser intrínseca ou extrínseca; b) interesse, que estimula o pensamento e a atenção; c) habilidade de compartilhar experiências, definida por Santos $(2008$, p. 37) como "o reconhecimento de que novas aprendizagens podem beneficiar-se das anteriores porque o fato de aprender uma coisa pode ajudar a aprender outras [...]"; d) habilidade de interagir com os diferentes contextos, dado que os diferentes cenários, por serem estimulantes na perspectiva dos alunos, propiciam e facilitam a aprendizagem.

Considerando essas questões, o Brasil (2014), através da Base Nacional Comum Curricular (BNCC), orienta 10 competências gerais da educação básica voltadas não só à questão cognitiva, como também ao desenvolvimento de habilidades direcionadas à formação de atitudes e valores. Nesse contexto, as atividades desenvolvidas voltadas às metodologias de aprendizagem ativa só têm a favorecer o aprendizado, principalmente quando vêm acompanhadas de objetos de aprendizagem construídos com o auxílio da robótica, causando motivação, interesse, diferente cenário e a possibilidade de compartilhamento de outras experiências. Podemos exemplificar com a competência 5 (BRASIL, 2014, p. 9), que enuncia "compreender, utilizar e criar tecnologias [...] de forma crítica, significativa, reflexiva [...]" e também a competência 7, que destaca "argumentar com base em fatos, dados e informações confiáveis, para formular, negociar e defender ideias, pontos de vista e decisões comuns [...]".

\section{MATERIAIS E MÉTODOS}

\section{MATERIAIS}

A construção da impressora foi baseada em peças de conjuntos para robótica, nesse caso do LEGO $^{\circ}$ Mindstorms, versão RCX, e sua estrutura pode ser vista na Figura 1. A impressora foi montada por dois bolsistas de Iniciação Científica da graduação, que cursam Engenharia de Controle e Automação, por intermédio de projeto de pesquisa voltado ao desenvolvimento de OA para o ensino de Física e Matemática.

Na montagem, para executar as movimentações necessárias, foram utilizados dois motores de passo e um motor DC. Um dos motores de passo é utilizado para deslocar o papel de forma horizontal, nos sentidos frente e trás, sendo que o sistema responsável por essa ação - identificado como o item 1 na Figura 1 - utiliza ainda rodas como guias para a folha de papel, evitando, assim, a torção da mesma. O segundo motor de passo é encarregado da locomoção do cabeçote de sustentação da caneta. Implementado a partir de um conjunto de engrenagem e cremalheira - indicado como o item 2 na Figura 1 - o sistema realiza o movimento lateral fazendo a caneta se deslocar para a direita ou para a esquerda. Esses elementos são responsáveis pelos dois eixos de movimentação da impressora. Um motor DC de proporç̃̃es pequenas e baixo torque foi utilizado para realizar o movimento vertical da caneta, colocando-a ou não em contato com o papel. O sistema que executa essa tarefa é identificado como o item 3 na Figura 1. 
Figura 1 - Visão geral de impressora, com destaque para os sistemas responsáveis pela

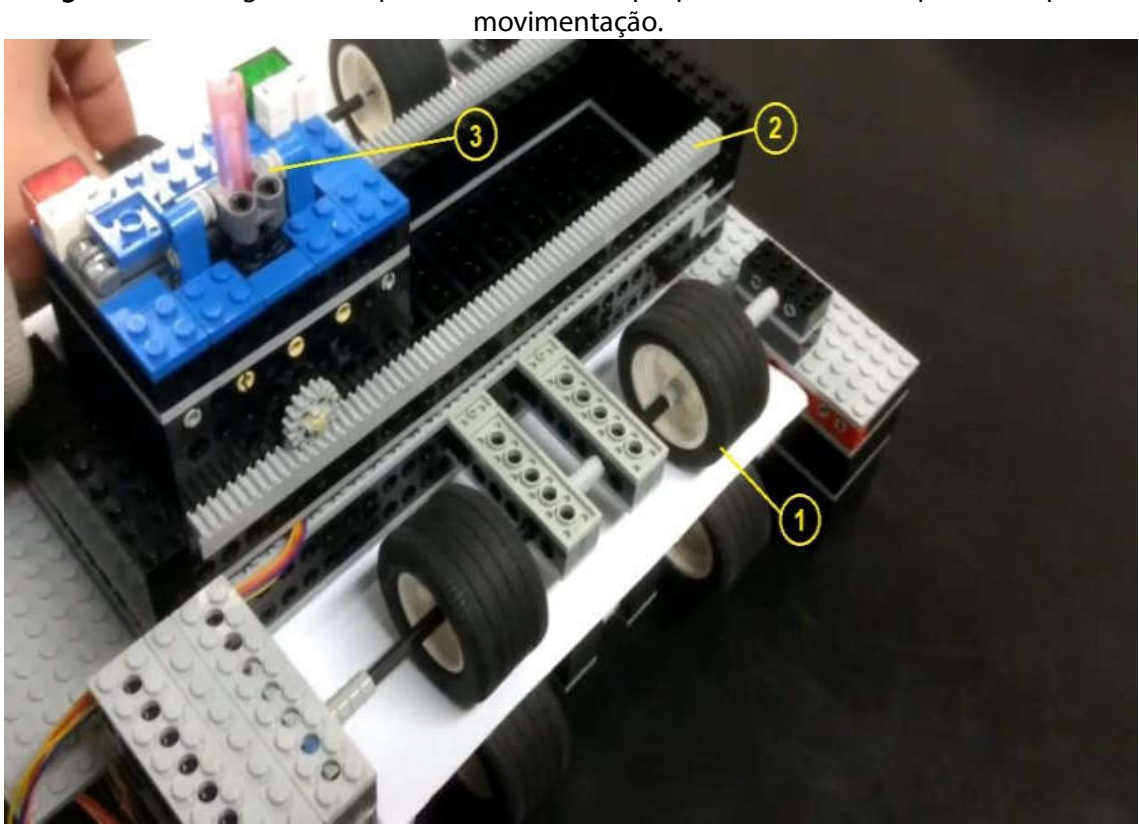

Fonte: Autor.

Para a interface com o usuário, que permite que este forneça as informações necessárias para a elaboração da imagem, foi desenvolvido um aplicativo para dispositivos Android, mostrado na Figura 2, utilizando a plataforma MIT App Inventor. Nessa interface são informadas características de segmentos de reta (ponto inicial, ângulo e comprimento) que serão transferidas para o Arduino, o qual controlará o movimento dos motores a fim de esboçar as figuras desejadas. A comunicação entre o aplicativo do celular e a plataforma Arduino é realizada através de uma conexão Bluetooth.

As ferramentas descritas foram desenvolvidas especificamente para a aplicação, mediada por conceitos matemáticos. As escolhas das plataformas e elementos de hardware foram baseadas na disponibilidade dos modelos citados, bem como na utilização em código aberto, não necessitando o investimento em licenças de software. 
Figura 2 - Aplicativo desenvolvido para informação dos dados referentes às figuras a serem traçadas pela impressora.

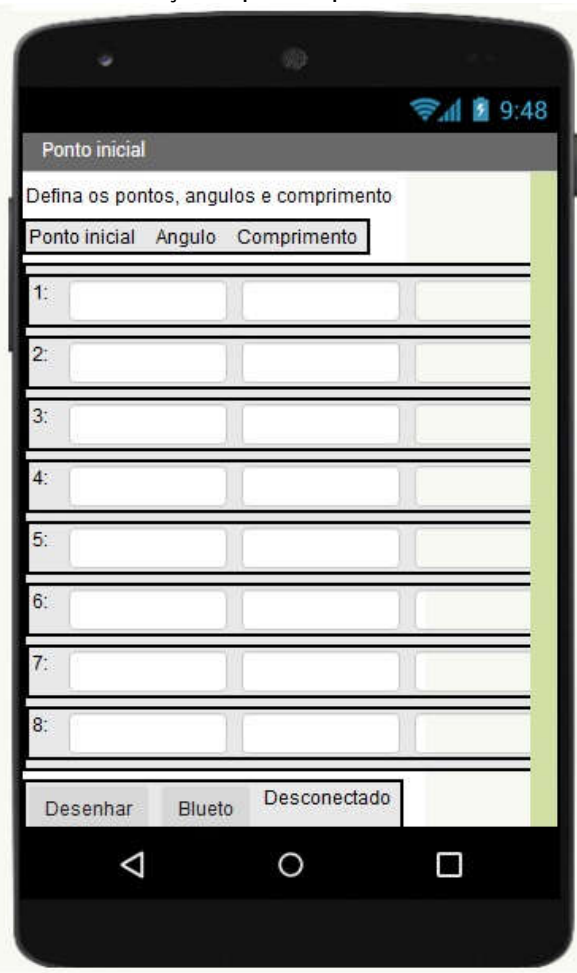

Fonte: Autor

\section{MetOdOLOGIA}

O OA desenvolvido tem o objetivo de ser utilizado em conjunto com conceitos matemáticos relacionados à Geometria, como representação em sistema cartesiano e polígonos, por exemplo. A aplicação descrita refere-se à associação da impressora com noções de Geometria Plana, que é a área da Matemática que estuda o comportamento de estruturas no plano, com base em conceitos como ponto, reta e plano.

No caso da atividade elaborada, pretendia-se traçar figuras geométricas planas, a partir da descrição dos segmentos de retas que as compõem. Dessa forma, cada polígono (limitado a uma figura com no máximo 10 lados) deve ser decomposto em segmentos de reta identificados com as informações acerca de seu comprimento e do ângulo de inclinação com relação ao plano horizontal, podendo esse ser positivo ou negativo.

Para a realização da atividade, o grupo deveria analisar as figuras recebidas e, partindo de um vértice escolhido como ponto inicial - e, posteriormente indicado como ponto $(0,0)$-, descrever cada segmento de reta com um par de dados: comprimento e 
MORALES, A. C.; GIACOMELLI, P.; MORO, T. B.; CATELLI, F.

ângulo. Os valores obtidos seriam informados no aplicativo (que, nesse caso, utiliza apenas as duas últimas colunas de dados). Após a descrição de todos os segmentos que compõem a figura, esses valores são transferidos ao controlador (Arduino que identifica os dados descritos no aplicativo e transfere as informações para a impressora que executa a impressão da figura geométrica), e a impressora traça as respectivas retas.

\section{DESENVOLVIMENTO DAS ATIVIDADES}

Essa atividade foi desenvolvida em uma turma de $2^{\circ}$ ano do Ensino Médio em uma escola particular do município de Caxias do Sul, Rio Grande do Sul. A escolha dessa turma foi baseada na realização do estudo de conceitos de geometria plana no início de 2018, mesmo ano em que foi aplicada a atividade, que no dia contava com a professora de matemática da turma e também com a professora pesquisadora do projeto. Os grupos, constituídos por até 5 alunos, receberam uma figura geométrica cada, com a medida de seus lados. O objetivo era partir de um ponto identificado como o zero da figura e calcular cada segmento de reta considerando o último ponto traçado. Assim, os estudantes precisaram calcular o ângulo de cada reta com relação ao eixo horizontal, partindo sempre do último traçado.

No primeiro momento as professoras não interferiram no desenvolvimento da atividade, o auxílio somente foi realizado nas dúvidas sobre o que calcular. Ao concluir os cálculos, os integrantes de cada grupo se dirigiam até o aplicativo para digitar os valores encontrados, que consistiam no comprimento da reta e seu respectivo ângulo. Após o envio dos dados, a impressora desenhava a imagem no papel. No caso do desenho não estar de acordo com o solicitado, o grupo precisava refazer os cálculos e imprimir a figura novamente.

Dos 6 grupos que trabalharam na atividade, 4 deles a desenvolveram de forma correta já na primeira tentativa e, ao imprimirem suas figuras, elas apresentaram o formato desejado. Porém, 2 grupos não obtiveram o mesmo mérito e, após a impressão de suas figuras, foi possível verificar (Figura 3) que os ângulos foram calculados erroneamente. As figuras corretas podem ser verificadas na Figura 5.

Na Figura 3a, podemos observar que a figura geométrica teve sua impressão iniciada pelo canto inferior direito, conforme numeração (1), traçada uma reta vertical. $\mathrm{Na}$ sequência foram desenhadas duas retas inclinadas na parte superior (2 e 3) e, por fim, foi traçado um segmento de reta inclinado (4), o qual deveria ser vertical e paralelo à primeira. Um ângulo digitado de forma errada impossibilitou o desenho da figura geométrica original. Já a Figura 3b iniciou também pelo canto inferior direito, realizou a reta horizontal para a esquerda (1), subiu em ângulo para a esquerda (2) e depois para direta (3), quando teve o ângulo errado que resultou em uma reta horizontal para a esquerda ao invés da direita (4 e 5). 
Figura 3 - Impressões das figuras geométricas com ângulos errados.

a)

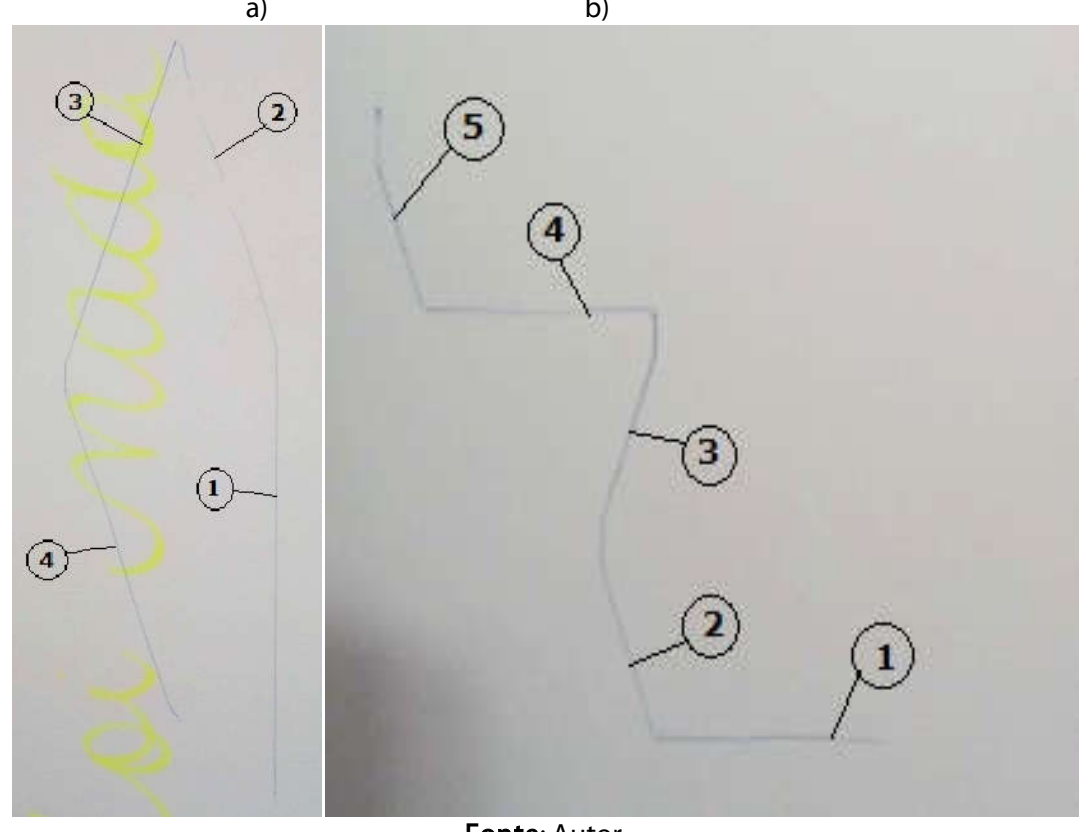

Fonte: Autor

Após esses resultados, houve a interferência de uma das professoras junto aos grupos. Ao observar os cálculos realizados, foi fácil identificar onde se encontrava o erro. Na realidade, em um dos grupos, o problema não estava no cálculo, mas na forma com que o ângulo fora observado e repassado para o aplicativo. Já o outro grupo realmente realizou o cálculo do ângulo incorretamente. Em nenhum dos casos a resposta foi fornecida pela professora. A interferência foi de forma a induzir que cada grupo encontrasse seus erros, através de uma proposta reflexiva e crítica. Nas Figuras 4a e 4b pode-se visualizar a resolução dos cálculos dos grupos. 
MORALES, A. C.; GIACOMELLI, P.; MORO, T. B.; CATELLI, F.

a)

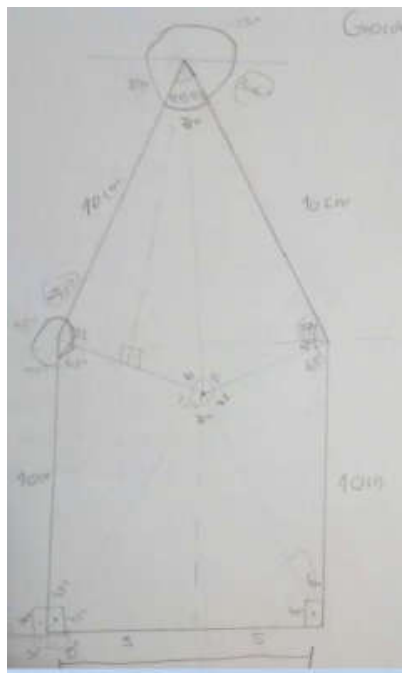

Figura 4 - Cálculos dos ângulos

b)

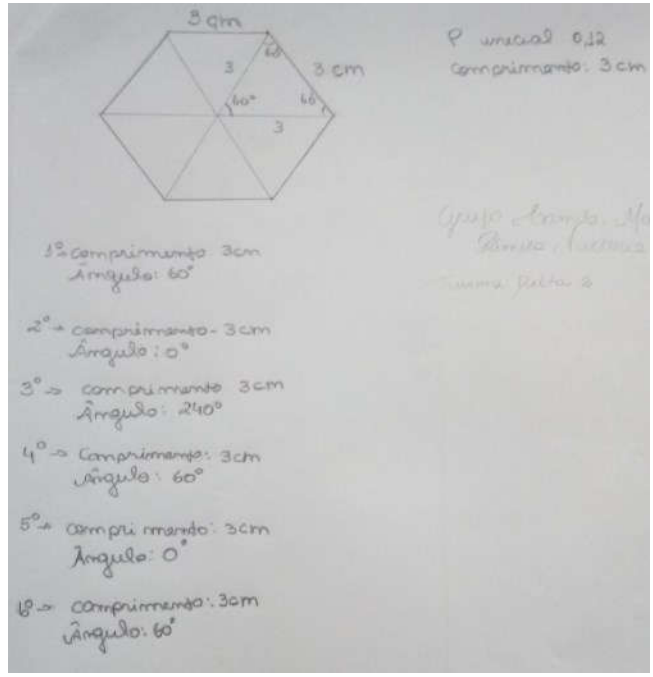

Fonte: Autor

Após a conclusão dos novos cálculos, foi realizada uma segunda tentativa de impressão das figuras geométricas, o que resultou na correta impressão das mesmas. Estas podem ser visualizadas nas Figuras 5a e 5b.

Figura 5 - Reimpressão das figuras geométricas

a)

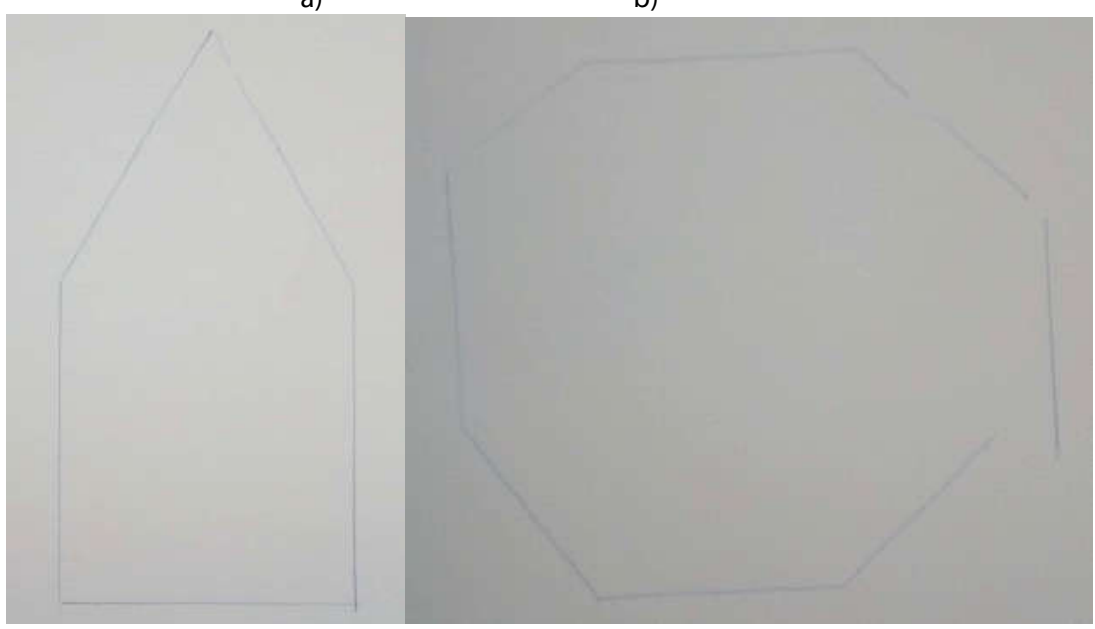

Fonte: Autor

$\mathrm{Na}$ Figura 5a podemos visualizar a figura geométrica impressa de forma perfeita, já na Figura $5 \mathrm{~b}$ visualiza-se que a figura geométrica não teve um perfeito fechamento de suas partes, porém essa imperfeição deve-se ao fato de um 
escorregamento da caneta na finalização, o que resultou nessa imperfeição que evidentemente não foi provocada por nenhuma ação inadequada dos alunos executores.

\section{CONSIDERAÇÕES FINAIS}

Nesse trabalho foi possível observar quesitos importantes para um processo de formação integral dos estudantes envolvidos. Proporcionando uma metodologia de aprendizagem ativa, através de um objeto de aprendizagem construído com o auxílio da robótica, foi possível trabalhar, de forma diferenciada, o conteúdo referente à Geometria Plana em uma turma do $2^{\circ}$ ano do Ensino Médio. Primeiramente observamos o interesse, a curiosidade e a motivação pela utilização do objeto de aprendizagem. Como a atividade foi desenvolvida em grupo, os estudantes tiveram a oportunidade de compartilhar experiências, além de estarem envolvidos em um contexto diferenciado daquele da aprendizagem tradicional. Neste aspecto, é possível citar um dos grupos que, ao chegarem a impressora para digitar os valores calculados, um dos colegas questionava o cálculo utilizado pelo grupo, que pode ser visualizado como incorreto através da Figura 3a. Com a visualização do erro pela impressão, este aluno uniu novamente o grupo para expor a sua percepção sobre o cálculo, o que resultou na correta impressão da figura geométrica (Figura 5a).

Destacamos como diferencial nessa atividade a oportunidade que os estudantes tiveram de testar na prática seus cálculos, tendo a possibilidade de eles mesmos identificarem seus erros. O que vai ao encontro das diretrizes curriculares do Brasil (2014) na promoção de metodologias que busquem formar um indivíduo crítico e reflexivo. Assim, essa atividade proporcionou a utilização de habilidades voltadas ao trabalho em equipe, à reflexão sobre seus cálculos, através do erro, além da curiosidade pelo funcionamento do OA. Também foi possível perceber, nos diferentes grupos, uma variação dos métodos de cálculos, ressaltando aos professores os diferentes modos de compreensão sobre um mesmo conteúdo.

Desse modo, podemos afirmar que, potencialmente, atividades voltadas à $A A$, com a utilização de OA, favorecem a emergência da motivação e do interesse, além de proporcionarem a integração entre os estudantes, possibilitando o compartilhamento de experiências; o leitor reconhecerá aqui os quatro elementos, evidenciados por Santos (2008), que promovem a ocorrência da aprendizagem.

Ressaltamos também que esse estudo não visava propriamente à aprendizagem, pois para sua avaliação é preciso o desenvolvimento de critérios específicos, o que não foi o escopo da atividade, mas sim a aplicação do OA em si, com o objetivo de observar aspectos como a participação, a interação, a motivação e o interesse dos estudantes perante seu uso. Nessa perspectiva, há a possibilidade do desenvolvimento de atividades futuras com a utilização do mesmo OA, porém com um foco mais voltado diretamente à aprendizagem.

Artigo recebido em: $17 / 08 / 2020$ Aprovado para publicação em: 03/11/2020 
MORALES, A. C.; GIACOMELLI, P.; MORO, T. B.; CATELLI, F.

PRINTER BUILT FOR LEGO: A LEARNING OBJETC FOR PLANE GEOMETRY APPLICATION

ABSTRACT: This article deals with the use of a printer built with LEGO by scientific initiation fellows from the Control and Automation Engineering course, as a learning object for an application of the content of Plane Geometry. The theoretical framework is subsidized by learning objects and active learning methodologies and it supported the development of the activity that consisted of, a given geometric figure, calculating the angles in sequence to form the required figure. Subsequently, the line length and angle were typed in sequence in the application that communicates to the printer, which prints the image. Through the result it was possible to identify any errors in the calculations, with the teacher's interference for their understanding and subsequent correction by the students. The activity provided motivation and interest, mediated by teamwork, in addition to a reflective analysis on the learning of content.

KEYWORDS: Active learning, Learning object, Learning methodologies, Plane geometry.

IMPRESORA CONSTRUIDA DE LEGO : UN OBJETO DE APRENDIZAJE PARA APLICA GEOMETRÍA PLANA

RESUMO: Este artículo trata sobre el uso de uma impressora contruida com LEGO por becarios de iniciación científica del curso de Ingeniería de Control y Automtización, como objeto de aprendizaje para uma aplicación del contenido de Geometria Plana. El marco teórico, subvencionado por objetos de aprendizaje y metodologias de aprendizaje activo, apoyó el desarrollo de la actividad que consistió em, dada uma figura geométrica, calcular los ángulos em secuencia para formar la figura requerida. Posteriormente, la longitude de la línea y el ángulo se escribieron em secuencia em la aplicación que se comunica com la impressora, que imprime la imagen. A través del resultado se pudo identificar cualquier error em los cálculos, com la interferencia del docente para la conprensión y posterior correción por parte de los alumnos. La atividade generó motivación e interés, mediado por el trabajo en equipo, y um análisis reflexivo sobre el aprendizaje del contenido.

PALABRAS CLAVES: Aprendizaje activo, Objeto de aprendizaje, Metodologías de aprendizaje, Geometria plana.

\section{REFERÊNCIAS}

ALMEIDA, M. E. B. Apresentação. In: BACICH, L.; MORAN, J. (org.). Metodologias ativas para uma educação inovadora: uma abordagem téorico-prática. Porto Alegre: Penso, 2018.

BES, P. et al. Metodologias para aprendizagem ativa. Porto Alegre, Editora: Sagah, 2019. 
BRASIL - BNCC - Base Nacional Comum Curricular - Ensino Médio, 2014. Disponível em: http://basenacionalcomum.mec.gov.br/images/historico/BNCC_EnsinoMedio_embaixa_ site_110518.pdf. Acesso em: 14 maio 2020.

DEWEY, J. Experiência e educação. Tradução de Anísio Teixeira, São Paulo, Editora: Nacional, 1976.

NESI, T. L. et al. Objetos de Aprendizagem de Matemática: um panorama do que diz em alguns estudos no Brasil. Renote, Porto Alegre, v. 17, n. 1, p. 557-566, jan. 2019. Disponível em: https://seer.ufrgs.br/renote/article/view/96516/54169. Acesso em: 15 maio 2020.

PUHL, C.S. et al. Revisão de problemas e sensoriamento remoto: em busca de uma aprendizagem ativa com estudantes do $9^{\circ}$ ano. Renote, Porto Alegre, v.15, n.2, 2017. Disponível em: https://seer.ufrgs.br/renote/article/view/79243. Acesso em: 11 maio 2020.

SANTOS, J.C.F. Aprendizagem significativa: modalidades de aprendizagem e o papel do professor. Porto Alegre, Editora: Mediação, 2008.

SANTOS, C.E.M., LEITE, B.S. Construção de um jogo educativo em uma plataforma de desenvolvimento de jogos e aplicativos de baixo grau de complexidade: o caso do Quizmica - Radioatividade. Renote, Porto Alegre, v.17, n.2, p.193-202, 2019. Disponível em: https://seer.ufrgs.br/renote/article/view/95725. Acesso em: 11 maio 2020.

TAROUCO, L. M. R. et al. Objetos de Aprendizagem: teoria e prática. Porto Alegre: Evangraf, 2014. 506 p. Disponível em:

http://penta3.ufrgs.br/ObjetosAprendizagem/LivroOA-total.pdf. Acesso em: 14 maio 2020.

WILEY, D. A. (2000). Connecting learning objects to instructional design theory: A definition, a metaphor, and a taxonomy. In: The Instructional Use of Learning Objects. Disponível em: http://gcc.unipaderborn.de/www/WI/WI2/wi2_lit.nsf/d2f7ed56380ef2fdc125683100441206/75a1e53e 5094cf05c12570c300637606/\$FILE/wiley-1.pdf. Acesso em: 14 maio 2020.

ZARPELON, E. et al. Repositórios de objetos de aprendizagem: uma breve caracterização e discussão a partir dos recursos disponibilizados em três bancos de dados. Revista Electrónica de Investigación En Educación En Ciencias, Buenos Aires, v. 13, n. 2, p.4761, jul. 2018. Semestral. Disponível em:

http://ppct.caicyt.gov.ar/index.php/reiec/article/view/14177/45454575759187. Acesso em: 03 jun. 2019. 
MORALES, A. C.; GIACOMELLI, P.; MORO, T. B.; CATELLI, F.

Andréa Cantarelli Morales. Doutoranda em Educação pela Universidade de Caxias, bolsista CNPq PROSUC/CAPES, Mestra em Educação pela mesma Instituição e Tecnóloga em Automação Industrial e Licenciada em Matemática. Professora da área do conhecimento das Ciências Exatas na Universidade de Caxias do Sul. Atualmente com projeto de tese voltado às influências na escolha da profissionalização de mulheres que

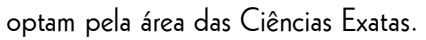

Orcid: https://orcid.org/0000-0003-1276-8191

Email: acmorales.morales@smail.com

Patrícia Giacomelli. Possui graduação em Engenharia Elétrica pela Universidade de Passo Fundo (2000), Mestrado em Engenharia Elétrica pela Universidade Federal de Santa Catarina (2003) e Pós-graduação em Docência na Educação Profissional e Tecnológica pelo SENAI CETIQT - Centro de Tecnologia da Indústria Química e Têxtil (2014). Atualmente é professora da Universidade de Caxias do Sul. Tem experiência na área de Engenharia Elétrica, com ênfase em Microeletrônica e Automação Industrial.

Orcid: https://orcid.org/0000-0002-8493-9693

Email: pgiacomelli1@ucs.br

Tatiele Bolson Moro. Possui Graduação em Sistemas de Informação pela Universidade Franciscana (2009), Graduação em Programa Especial de Formação de Professores para a Educação Profissional pela Universidade Federal de Santa Maria (2013) e Mestrado em Nanociências pela Universidade Franciscana (2012). Doutoranda em Educação pela Universidade de Caxias do Sul. Atualmente é Tecnóloga da Informação do Instituto Federal do Rio Grande do Sul. Tem experiência na área de Ciência da Computação, com ênfase em Sistemas de Informação, atuando principalmente nos seguintes temas: Educação Inclusiva, Tecnologias Assistivas, Tecnologia de Informação e Comunicação, Tecnologias Educacionais.

Orcid: https://orcid.org/0000-0002-3302-8953

Email: tati.bm@gmail.com

Francisco Catelli. Possui Graduação em Licenciatura em Física pela Universidade Federal do Rio Grande do Sul (1976), Mestrado em Engenharia de Minas, Metalúrgica e de Materiais pela Universidade Federal do Rio Grande do Sul (1981) e Doutorado em Educação - Universite Laval (1995). Atualmente é professor titular da Universidade de Caxias do Sul. Tem experiência na área de Educação, com ênfase em Teorias da Instrução - interdisciplinaridade, atuando principalmente nos seguintes temas: ensino de ciências, divulgação científica, experimentos com material alternativo, laboratório de física e óptica.

Orcid: https://orcid.org/0000-0002-2484-7711

Email: fcatelli@ucs.br

Este periódico utiliza a licença Creative Commons Attribution 3.0, para periódicos de acesso aberto (Open Archives Iniciative - OAI). 